\title{
AC 2010-1381: EFFORTS TO BETTER UNDERSTAND THE RELATIONSHIP BETWEEN CIVIL ENGINEERING STUDENT PREPARATION AND SUCCESS ON THE FUNDAMENTALS OF ENGINEERING EXAM
}

James Bowen, University of North Carolina, Charlotte 


\title{
Efforts to Better Understand the Relationship Between Civil Engineering Student Preparation and Success on the Fundamentals of Engineering Exam
}

\begin{abstract}
Like many other programs in Civil and Environmental Engineering, the majority of students at our University take the Fundamentals of Engineering (FE) exam. While not currently required for graduation, students, faculty, and employers alike see passing the FE exam as an important first step in a Civil Engineering career. Historically, FE pass rates at our University have slightly trailed both national averages and those for our Carnegie classification-based comparator group for those students taking the Civil Engineering specific afternoon exam. The relative difference in pass rates, however, has been quite variable over the years. Recently, department faculty have responded to this situation by conducting an analysis of curriculum issues related to student preparation for the FE exam and by implementing new measures designed to improve student preparation and FE exam pass rates. An analysis of the most recent test performance found that there was a statistically significant difference between our students' performance on the AM and PM exam, with the PM exam performance exceeding the AM exam performance. A comparison of the performance weighted according the relative numbers of questions for a particular topic for the AM and PM found that $67 \%$ of the overall difference in FE exam performance between our students and students in our comparator group was attributable to our students' performance on the morning exam. Furthermore, much of the difference in performance on the AM exam for our students was concentrated in just a few topics. To improve student performance Department faculty have begun a program to improve both student preparation and motivation with the aim of achieving FE exam pass rates that meet or exceed the national averages.
\end{abstract}

\section{Introduction}

Studying for, taking, and passing the Fundamental of Engineering (FE) exam is a necessary rite of passage in the Civil and Environmental Engineering professions. Most firsttime test takers of the FE exam are undergraduate students within an ABET accredited Engineering program. For many of these programs, the FE exam serves not only as a stepping stone for students embarking on their Engineering career, but also as an assessment tool for the undergraduate Engineering program. Many schools use results of the FE exam for program assessment $^{1,2,3}$, which is often a component of the learning outcome assessment associated with ABET accreditation ${ }^{4}$. A few programs make passing the FE exam a graduation requirement ${ }^{4}$.

While the uses of the FE exam results are varied and numerous, interest in the FE exam pass rate is keen with many Engineering faculty, and these faculty are often actively involved in documenting, analyzing, and working to improve FE exam pass rates for their Department. This 
is certainly the case for our faculty in the Department of Civil and Environmental Engineering at the University of North Carolina at Charlotte. Our interest in the FE exam performance is also due to our ABET outcomes assessment process. We, like many other Departments, use our students' FE exam performance as part of an ABET outcomes assessment. In doing these assessments, however, we use many metrics, and do not explicitly consider our students' FE exam pass rates as an assessment metric. Nonetheless we recognize that many of our stakeholders use FE exam pass rates as a quality measure of our Department despite evidence in the literature of its limited value at the program level. ${ }^{5}$

Historically our FE exam pass rate has lagged both the national rate and that of our Carnegie classification-based comparator group. Our comparator group as designated by the National Council of Examiners for Engineering and Surveying (NCEES) is currently the Carnegie Foundation's Bal/HGC designation (Balanced arts \& sciences/professions, high graduate coexistence). Prior to 2009 we were part of the Research Intensive (RI) comparator group. Looking at overall FE exam pass rates over the past few years, until just recently the trend seemed to be towards relatively better performance by our students. As of 2005 our FE exam pass rates were not significantly different than the national averages or for that of our comparator group, but most recently our pass rates have declined back to levels seen earlier in the decade.

Partly because of this decline in FE exam pass rate, Department faculty have recently formed a committee that seeks to better understand the factors that limit our students' FE exam pass rate, and seeks to ultimately raise those rates to at least the national average. At present we are in an initial data gathering and assessment phase of this effort. We have recently implemented some new measures aimed at improving our students' performance, but we have not yet assessed how effective these measures have been. In the meantime we are examining FE exam pass rate data from the past few years as part of our initial assessment. This article describes some of our recent work to analyze student performance on the FE exam, and to implement new measures designed to increase $\mathrm{FE}$ exam pass rates.

\section{An Analysis of Past FE Test Performance}

A quantitative retrospective analysis of $\mathrm{FE}$ exam performance was undertaken to better understand the characteristics of student performance and how it might relate to preparation for the FE exam. In analyzing these data we examined performance differences relative to our Carnegie Foundation classification-based comparator group. The observed differences between our students' performance on topics within the AM and PM exams and those of our comparator group were quantified using simple differences, giving results similar to the relative scores used by Wicker et al. ${ }^{2}$ and Nirmalakhandan et al. ${ }^{6}$. As we were ultimately interested in the consequences of these differences to student pass rates on the overall exam, we also weighted each deviation by the number of questions in that topic on either the AM or PM exam. As a way of interpreting these data, we also examined issues related to student preparation by comparing the list of FE exam topics within AM and PM test subject areas to that covered in our current Civil and Environmental Engineering curriculum. 
One common topic of conversation among Department faculty is how well the current curriculum prepares students for exam success. Currently students are offered quite a bit of flexibility in course selection, so that they may pursue both breadth and depth within the subdiscipline of Civil Engineering of their choosing. At present students may choose in their junior and senior years four electives within the Civil and Environmental Engineering Department and three additional technical electives in Science, Math, Engineering, or Business (Table 1). While a review of other Civil Engineering programs show some with significantly more flexibility than ours ${ }^{7}$, the consensus opinion within our faculty is that our curriculum is relatively flexible.

Table 1. Description of the Math, Science, and Engineering Courses within the Civil and Environmental Engineering Curriculum

\begin{tabular}{|l|l|l|}
\hline Area & $\begin{array}{l}\text { Number of } \\
\text { Credits }\end{array}$ & Classes \\
\hline Mathematics & 15 & Calculus I, II, III, Statistics, Differential Equations \\
\hline Science & 15 & $\begin{array}{l}\text { Chemistry I (w/lab), Physics I, II (w/ labs), Science } \\
\text { Elective }\end{array}$ \\
\hline $\begin{array}{l}\text { Engineering } \\
\text { Mechanics }\end{array}$ & 9 & $\begin{array}{l}\text { Statics, Solids, Engineering Science Elective } \\
\text { (Dynamics, Circuits, or Thermodynamics) }\end{array}$ \\
\hline $\begin{array}{l}\text { General } \\
\text { Engineering }\end{array}$ & 5 & $\begin{array}{l}\text { Introduction to Engineering I, II, Professional } \\
\text { Development }\end{array}$ \\
\hline $\begin{array}{l}\text { General Civil } \\
\text { Engineering }\end{array}$ & 16 & $\begin{array}{l}\text { Engineering Economics, Drawing, Surveying, } \\
\text { Sophomore Design, Senior Design I, II }\end{array}$ \\
\hline $\begin{array}{l}\text { Discipline- } \\
\text { Specific Civil } \\
\text { Engineering }\end{array}$ & 22 & $\begin{array}{l}\text { Transportation, Structures, Geotechnical, } \\
\text { Environmental (all w/ labs), Hydraulics and } \\
\text { Hydrology, Concrete or Steel Design }\end{array}$ \\
\hline $\begin{array}{l}\text { Technical } \\
\text { Electives }\end{array}$ & 9 & $\begin{array}{l}\text { Upper-level Math, Science, Engineering, or } \\
\text { Business courses }\end{array}$ \\
\hline $\begin{array}{l}\text { Civil } \\
\text { Engineering } \\
\text { Electives }\end{array}$ & 12 & $\begin{array}{l}\text { Upper-level Civil and Environmental Engineering } \\
\text { courses }\end{array}$ \\
\hline
\end{tabular}

This curriculum flexibility has resulted in considerable variability between students in the extent to which the body of knowledge needed for the FE exam has been covered within their coursework. For instance students are required only to take one of three "Engineering Science" courses (Dynamics, Thermodynamics, Electrical Circuits) that each make up part of the AM exam. Likewise, some topics on the PM Civil Engineering exam are not covered in any of the required courses (Table 2), although some students may take major electives courses that cover these topics. A second concern of the faculty is the degree to which courses taught outside the College of Engineering (e.g. Math and Statistics courses) have the necessary rigor and problem solving focus needed to adequately prepare students for the FE exam. For these reasons we wanted our analysis of FE exam performance to be topic specific, but also to provide information relevant to our students' overall performance on the FE exam. 
Table 2. Coverage of Civil Engineering PM Exam Topics in Required Coursework.

\begin{tabular}{|l|c|c|c|c|c|}
\hline \multicolumn{1}{|c|}{ Test Area } & $\begin{array}{c}\text { Percent of } \\
\text { Afternoon } \\
\text { Exam }\end{array}$ & $\begin{array}{c}\text { Topics } \\
\text { Within } \\
\text { Area }\end{array}$ & $\begin{array}{c}\text { Complete } \\
(>\mathbf{9 0 \%} \text { of } \\
\text { topics })\end{array}$ & $\begin{array}{c}\text { Partial } \\
\mathbf{( 1 0}-\mathbf{9 0 \%} \\
\text { of topics) }\end{array}$ & $\begin{array}{c}\text { None } \\
(<\mathbf{1 0 \%} \\
\text { of topics) }\end{array}$ \\
\hline \hline Surveying & 11 & 7 & 7 & & \\
\hline $\begin{array}{l}\text { Hydraulics and Hydrologic } \\
\text { Systems }\end{array}$ & 12 & 7 & 3 & 1 & 3 \\
\hline $\begin{array}{l}\text { Soil Mechanics and } \\
\text { Foundations }\end{array}$ & 15 & 12 & 12 & & \\
\hline Environmental Engineering & 12 & 7 & 4 & 3 & \\
\hline Transportation & 12 & 7 & 4 & 2 & 1 \\
\hline Structural Analysis & 10 & 6 & 2 & 3 & 1 \\
\hline Structural Design & 10 & 3 & 3 & & \\
\hline Construction Management & 10 & 7 & 1 & 1 & 5 \\
\hline Materials & 8 & 5 & 3 & 2 & \\
\hline
\end{tabular}

The analysis of FE exam pass rates for students taking the afternoon Civil Engineering exam for the period from October 2005 through October 2009 confirmed that our students are generally less likely to pass the exam as compared with students nationwide or as compared to our comparator group. We limited our analysis to this time period because starting in October 2005 new specifications, and thus new contents, were established by the National Council of Examiners for Engineering and Surveying as a basis for the AM exam. In addition, the FE exam pass rate data are based upon a comparison of first-time test takers only. There was quite a bit of temporal variability in the measured pass rate for our students, but much less so for the national and comparator group averages, as would be expected considering the much larger sample size of our comparator group. Comparator group averages between April 2004 and April 2008 varied between $60 \%$ to $80 \%$, while the pass rates for our students varied from $35 \%$ to $70 \%$ during this same time period. Pass rates for all groups dropped precipitously in the October 2008 exam, but have recovered since then. In 2006 and 2007 pass rates at our University were approaching $70 \%$, but they have declined since that time to approximately $50 \%$ (Figure 1 ). During this time period, there were no significant changes in the curriculum, entering student qualifications, or graduating student grade point average that might explain the changes seen in FE pass rates at our University.

We also examined student performance on each of the thirteen topics on the AM exam, and the nine topics on the Civil Engineering PM exam (Table 3) for two particular FE tests (April 2008, 2009). Results from these two dates were taken because they are recent and they have relatively large sample sizes compared to the October exams of these years. In both April 2008 and April 2009 the percentage of questions answered correctly varied significantly (Figure 2), with the best performance (more than 75\% correct) for topic 5 (Ethics and Business 
Figure 1. FE Exam pass rates for students taking the Civil Engineering PM exam at our University and the corresponding pass rates nationally and for the comparator group (Carnegie RI or Bal/HGC).

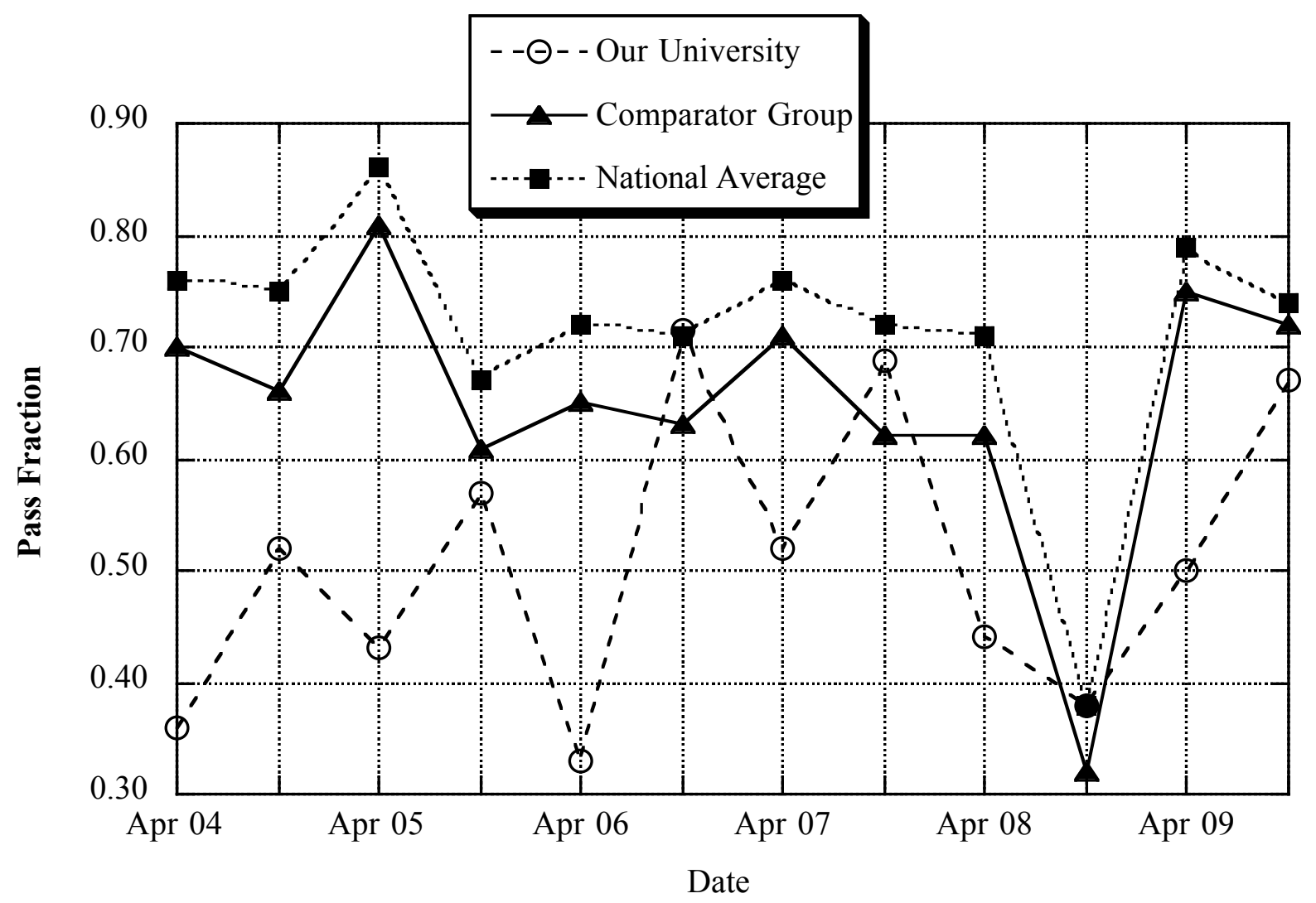

Table 3. Topics on the AM FE Exam and the Civil Engineering PM FE Exam

\begin{tabular}{|c|l|c|l|}
\hline No. & \multicolumn{1}{|c|}{ AM Topics } & No. & \multicolumn{1}{c|}{ PM Topics } \\
\hline \hline 1 & Mathematics & 14 & Advanced Engineering Mathematics \\
\hline 2 & Engineering Probability and Statistics & 15 & Engineering Probability and Statistics \\
\hline 3 & Chemistry & 16 & Biology \\
\hline 4 & Computers & 17 & Engineering Economics \\
\hline 5 & Ethics and Business Practices & 18 & Application of Engineering Mechanics \\
\hline 6 & Engineering Economics & 19 & Engineering of Materials \\
\hline 7 & Engineering Mechanics (Statics) & 20 & Fluids \\
\hline 8 & Engineering Mechanics (Dynamics) & 21 & Electricity and Magnetism \\
\hline 9 & Strength of Materials & 22 & Thermodynamics and Heat Transfer \\
\hline 10 & Material Properties & & \\
\hline 11 & Fluid Mechanics & & \\
\hline 12 & Electricity and Magnetism & & \\
\hline 13 & Thermodynamics & \\
\hline
\end{tabular}


Practices), and the poorest performance (approximately $40 \%$ correct) for topic 12 from the AM exam (Electricity and Magnetism. Exam performance on the afternoon exam was quite variable between the two tests (Figure 2), which may be due to the relatively small number of questions asked on topics such as Biology or Engineering Probability and Statistics, which make up less than $10 \%$ each of the afternoon exam of 60 questions.

What is most striking about the comparison of exam performance by topic between students at our University and students in the comparator group is the strong correlation between the two groups. In both the April 2008 and April 2009 tests, essentially the same pattern in performance is seen across the twenty-two topics (Figure 2) for the two groups of test takers. Both groups exhibit strong performance in the same topics (e.g. Ethics) and poor performance in the same topics (e.g. Electricity and Magnetism). Some differences in test performance are seen, however, between the two groups of test takers. In both April 2008 and April 2009, students at our University fared generally better in a relative sense on the PM exam as compared to the AM exam. In fact, in several topics for this exam, students at our University scored as well those of our comparator group. The same effect is seen in the April 2009 test, with our students' performance on the PM exam approaching that of our comparator group, while the AM exam performance was consistently below the comparator group performance (Figure 2), particularly on measures 10 to 13 (Figure 2).

The relative difference in percent correct by topic is a more sensitive measure of the performance of the two student groups, and has been used previously to assess FE exam performance ${ }^{2,6}$. This statistic was calculated for each exam topic of the AM and PM tests. Performance data were collected from nine implementations of the test beginning in October 2005 (October 2005 - October 2009), and were weighted by the number of test takers in that year both at our University and within our comparator group. The time-averaged differences in test performance by topic were then averaged for the AM and PM exams. On average students at our University scored $3.86 \%$ worse than students in the comparator group on the AM exam for the nine tests examined (October 2005 - October 2009), and 2.14\% worse than students nationwide on the Civil Engineering PM portion of the FE exam. This difference in AM vs. PM performance for our students relative to the comparator group was found to be significantly different at the $5 \%$ significance level using a t-test for differences in mean values.

To investigate how these differences in performance by topic might affect the overall test performance, the differences in percent correct by topic for the two groups were weighted by the relative number of questions on each topic (Table 3, Table 4). Analyzed this way, differences in performance on topics that are a relatively large portion of the exam (e.g. AM test Mathematics, PM test - Soil Mechanics) will assume a relatively larger importance. Using this weighting procedure, some interesting differences in test performance appear. First, the relatively poor performance by students at our University on the AM exam is seen even more clearly in the weighted relative differences. Differences in time-averaged performance on the AM exam accounts for $67.3 \%$ of the total weighted difference between our students and the comparator group, while the PM exam accounts for the remaining $32.7 \%$ of the weighted difference in FE exam performance. Furthermore, these weighted differences are concentrated in 

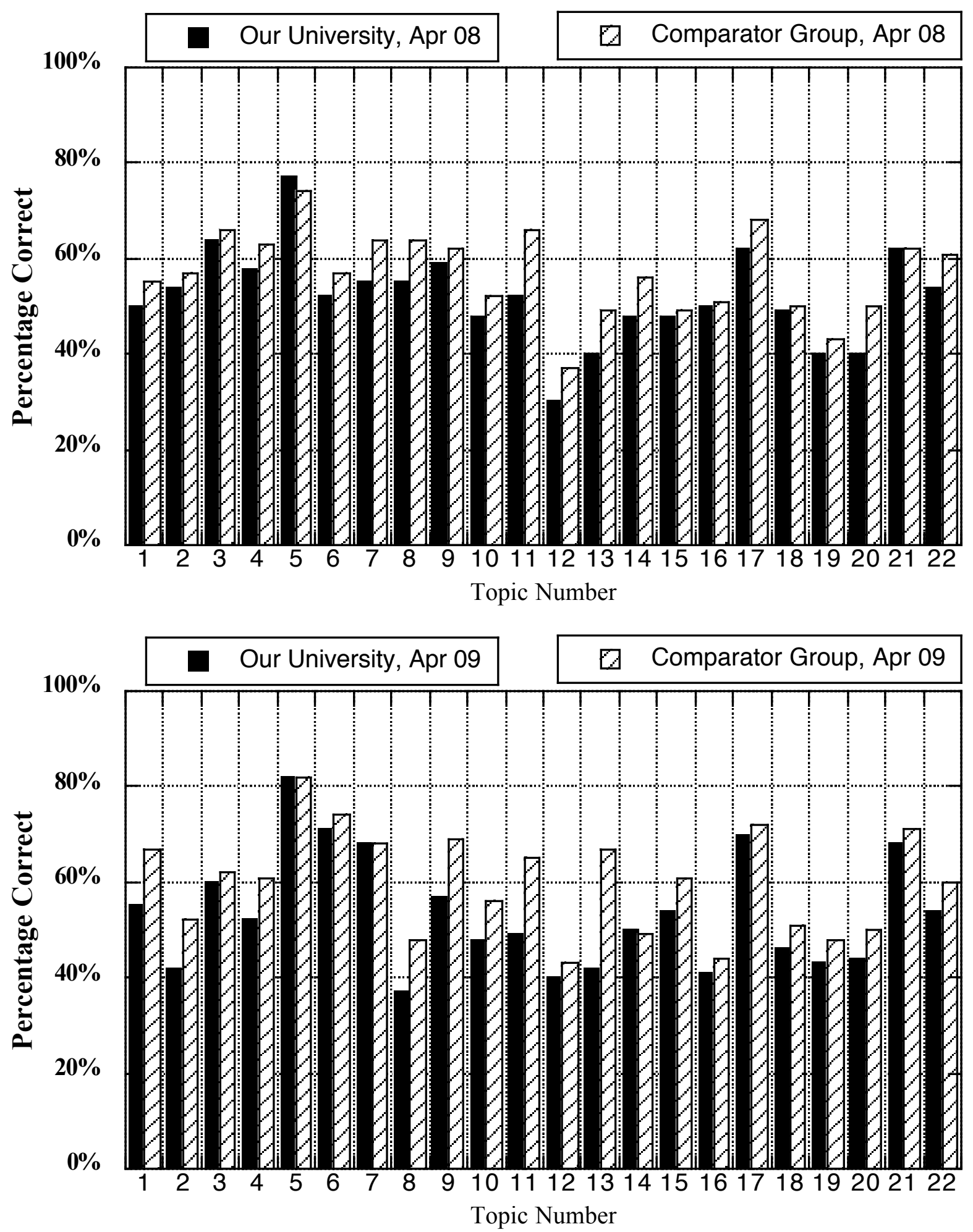

Figure 2. FE Exam Performance on the AM exam (topics 1-13) and the Civil Engineering PM exam (topics 14-22) for our University vs. the comparator group for the April 2008 (upper panel) and the April 2009 exams (lower panel). 
Table 4. Time-averaged differences in performance and weighted performance between Civil Engineering students at our University as compared with our comparator group (Carnegie RI or Bal/HGC) on individual topics within the AM and Civil Engineering PM portions of the FE Exam. Weightings are based upon the current number of questions in the AM and PM exams. The values in the right-most column are normalized to give a cumulative performance difference of $100 \%$. Nine exams were analyzed (October 2005 - October 2009).

\begin{tabular}{|r|l|r|r|r|}
\hline No. & \multicolumn{1}{|c|}{ AM Topics } & $\begin{array}{r}\text { Difference } \\
\text { in Percent } \\
\text { Correct }\end{array}$ & Weighting & $\begin{array}{c}\text { Weighted } \\
\text { Difference }\end{array}$ \\
\hline \hline 1 & Mathematics & 4.9 & $15.8 \%$ & $13.2 \%$ \\
\hline 2 & Engineering Probability and Statistics & 1.8 & $6.7 \%$ & $2.0 \%$ \\
\hline 3 & Chemistry & 2.8 & $9.2 \%$ & $4.3 \%$ \\
\hline 4 & Computers & 3.4 & $6.7 \%$ & $3.9 \%$ \\
\hline 5 & Ethics and Business Practices & -0.6 & $6.7 \%$ & $-0.6 \%$ \\
\hline 6 & Engineering Economics & 3.8 & $8.3 \%$ & $5.4 \%$ \\
\hline 7 & Engineering Mechanics (Statics) & 3.2 & $5.8 \%$ & $3.2 \%$ \\
\hline 8 & Engineering Mechanics (Dynamics) & 4.1 & $5.0 \%$ & $3.5 \%$ \\
\hline 9 & Strength of Materials & 1.1 & $6.7 \%$ & $1.3 \%$ \\
\hline 10 & Material Properties & 4.4 & $6.7 \%$ & $5.0 \%$ \\
\hline 11 & Fluid Mechanics & 8.3 & $6.7 \%$ & $9.5 \%$ \\
\hline 12 & Electricity and Magnetism & 5.1 & $9.2 \%$ & $8.0 \%$ \\
\hline 13 & Thermodynamics & 7.7 & $6.7 \%$ & $8.7 \%$ \\
\hline No. & & & & \\
\hline 14 & Surveying & 2.8 & $11.7 \%$ & $5.5 \%$ \\
\hline 15 & Pydraulics and Hydrologic Systems & 4.0 & $11.7 \%$ & $7.9 \%$ \\
\hline 16 & Soil Mechanics and Foundations & -1.6 & $15.0 \%$ & $-4.0 \%$ \\
\hline 17 & Environmental Engineering & 1.2 & $11.7 \%$ & $2.4 \%$ \\
\hline 18 & Transportation & 1.0 & $11.7 \%$ & $2.0 \%$ \\
\hline 19 & Structural Analysis & 2.8 & $10.0 \%$ & $4.7 \%$ \\
\hline 20 & Structural Design & 2.4 & $10.0 \%$ & $4.2 \%$ \\
\hline 21 & Construction Management & 1.7 & $10.0 \%$ & $2.8 \%$ \\
\hline 22 & Materials & 5.0 & $8.3 \%$ & $7.1 \%$ \\
\hline
\end{tabular}

a relatively small number of topics. For instance more than half of the weighted difference in the AM test performance $(39.3 \%$ of $67.3 \%$ ) comes from only four of the thirteen AM topics (Mathematics, Fluid Mechanics, Thermodynamics, Electricity and Magnetism). Similarly most of the difference in the afternoon performance (20.5\% of $32.3 \%)$ is due to only three of the nine topics (Surveying, Hydraulics and Hydrologic Systems, Materials). 


\section{Measures Taken to Improve FE Exam Performance}

Recently, department faculty have implemented several measures aimed at improving student preparation for the exam. The following four-part plan has been implemented:

1. Offer a formal weekly FE review class taught by department faculty, and require all seniors to attend the course,

2. Offer a four-hour FE mock exam on a Saturday morning two or three weeks prior to the actual FE exam,

3. Hold a "signing-day" ceremony attended by department faculty, with a presentation by a prominent alumnus, where students obtain the signatures needed for the FE exam application, and

4. Encourage department faculty teaching the Civil Engineering core curriculum to give some "FE-exam-style" questions on course quizzes and tests.

The first three of these measures is designed to improve student preparation and student motivation by encouraging and facilitating students' review of their Engineering coursework. Review courses that include motivational aspects and mock exams have been found to be effective in improving student performance ${ }^{9,10,11}$. The final measure is designed both to improve the students' familiarity with FE type questions, but also to improve student retention of information. Measures designed to improve knowledge retention have also been shown to be effective in improving Engineering test performance ${ }^{12}$. We are currently offering a review course that allots total review time in accordance with that topics importance to the overall test. While this was a reasonable starting point for review class assignments, considering our students' relatively poor performance on the AM portion of the exam, we may want to put more emphasis on the introductory Engineering "gateway" courses (e.g. Physics, Calculus, Statics \& Dynamics, Circuits, Strength of Materials). The importance of these courses to FE exam success has been noted by others ${ }^{4}$, as these courses prepare students for more advanced disciplinespecific study.

Our current plan is to continue with each of the measures listed above for the next few years while we continue to assess our students' performance on the FE exam. At present we do not anticipate any additional assessment methods beyond those described here that are based on calculating relative scores on individual exam topic relative to our comparator group. We do anticipate that through continuing assessment and further refinement of our efforts to prepare and motivate our students they will achieve FE exam pass rates that meet or exceed the rates seen nationally.

\section{Bibliography}

1. Balascio, C., Wehrle, L, Henry, R. and C Hollis. 2008. Nationally normed exams for outcomes assessment of Engineering Technology programs and certification of Engineering Technology graduates. Proceedings of the 2008 American Society for Engineering Education. Washington, D.C.: American Society for Engineering Education.

2. Wicker, R. B., Quintana, R, and A. Tarquin. 1999. Evaluation model using Fundamentals of Engineering examination. 1999. J. of Professional Issues in Engineering Education and Practice, Vol. 125, No. 2, April 1999, pp. 47-55. 
3. Koehn, E. and R. Mandalika. 2005. Curriculum outcome assessment using subject on the FE examination. Proceedings of the 2005 American Society for Engineering Education. Washington, D.C.: American Society for Engineering Education

4. Helgeson, R., and Wheeler, E. 2005. Passing the Fundamentals of Engineering examination as a graduation requirement in a general Engineering program: Lessons learned. Proceedings of the 2006 American Society for Engineering Education. Washington, D.C.: American Society for Engineering Education.

5. Lawson, W. D. 2007. Reliability and validity of FE exam scores for assessment of individual competence, program accreditation, and college performance. Journal of Professional Issues in Engineering Education and Practice, 133(4), 320-326.

6. Nirmalakhandan, N., Daniel, D., \& White, K. 2004. Use of subject-specific FE Exam results in outcomes assessment. Journal of Engineering Education, Vol 93, No. 1, pp. 73-77.

7. Gnanapragasam, N., Kuder K. and D. Jefferey. 2008. Comparison between grade earned in a course and performance in a simulated FE exam for mechanics related courses. Proceedings of the 2008 American Society for Engineering Education. Washington, D.C.: American Society for Engineering Education.

8. Nixon, W. and J. Stoner. 2009. Impacts of student course selection on subsequent career trajectories. Proceedings of the 2009 American Society for Engineering Education. Washington, D.C.: American Society for Engineering Education.

9. Estell, J.K. 2006. Using a JAVA certification book and mock exam in an introductory programming course. Proceedings of the 2005 American Society for Engineering Education. Washington, D.C.: American Society for Engineering Education.

10. Koehn, E. and R. Mandalika. 2005. Review for and assessment of the Fundamentals of Engineering exam. Proceedings of the 2005 American Society for Engineering Education. Washington, D.C.: American Society for Engineering Education.

11. Koehn, E. 1989. Fundamentals of Engineering exam: Motivation/review enhances pass rate. J. of Professional Issues in Engineering Education and Practice, Vol. 115, No. 3, July 1989, pp. 289-296.

12. Waters, C.K., and P. Rojeski. 2005. Retention of information - Improving the Engineering outcomes. Proceedings of the 2005 American Society for Engineering Education. Washington, D.C.: American Society for Engineering Education. 